\title{
PENGARUH KUAT LENTUR BETON TERHADAP PENAMBAHAN SERAT TANDAN KOSONG KELAPA SAWIT
}

\author{
Muliadi $^{1)}$, Sofyan ${ }^{2)}$, Yusti Hajar ${ }^{3)}$ \\ Jurusan Teknik Sipil, Fakultas Teknik, Universitas Malikussaleh \\ email: muliadi.eng@gmail.com, sofyan.ahmad93@yahoo.com,yustihajar@gmail.com
}

DOI: http://dx.doi.org/10.29103/tj.v8i2.156

\begin{abstract}
Abstrak
Beton merupakan salah satu bahan konstruksi yang telah umum digunakan untuk bangunan gedung, jembatan, jalan, dan lain-lain. Kelemahan beton sebagai bahan konstruksi adalah kuat lentur yang rendah dan sifatnya yang getas. Perbaikan kelemahan sifat beton tersebut bisa dengan menambahkan serat (fiber) dalam adukan beton. Bahan campuran beton antara lain yaitu semen, agregat halus, agregat kasar, air dan bahan tambah lainnya (zat adiktif, serat). Pada penelitian ini bahan tambah yang digunakan adalah serat tandan kosong kelapa sawit (STKKS). Tujuan Penelitian ini mengetahui pengaruh penambahan serat tandan kosong kelapa sawit terhadap kuat lentur beton pada setiap variasi serat. Proses pengelolahan serat yaitu serat direndam dan dibilas menggunakan $10 \%$ larutan $\mathrm{NaOH}$ selama 12 jam kemudian dikeringkan didalam oven, panjang serat yang digunakan $40 \mathrm{~mm}$. Variasi persentase serat dengan mengurangi berat volume semen di dalam campuran adalah 0\%, 5\%, 10\%, 15\%, $20 \%$. Hasil Kuat lentur rata-rata yang dihasilkan pada tiap-tiap variasi serat yaitu $0 \%(3,51$ Mpa), 5\% (4,18 Mpa), 10\% (4,09 Mpa), 15\% (4,53 Mpa), dan 20\% (4,62 Mpa). Dari penelitian ini menunjukkan bahwa penggunaan serat pada campuran beton menunjukkan kenaikan terhadap kuat lentur beton pada titik persentase serat $5 \%$, $10 \%, 15 \%$, dan $20 \%$, bila dibandingkan dengan beton normal $(0 \%)$.
\end{abstract}

Kata kunci: kuat lentur, serat tandan kosong kelapa sawit, beton.

\begin{abstract}
Concrete is one of Concrete is one of the construction materials that has been commonly used for buildings, bridges, roads, and others. The weakness of concrete as a construction material is its low flexural strength and brittle nature. Improving the weakness of the concrete properties can be by adding fiber in the concrete mixture. Concrete mixtures include cement, fine aggregates, coarse aggregates, water and other added ingredients (addictive substances, fibers). In this study the added ingredients used were oil palm empty bunches fibers (STKKS). The purpose of this study was to determine the effect of adding oil palm empty bunches fibers to the flexural strength of concrete in each variation of fiber. The process of processing fiber, namely fiber soaked and rinsed using $10 \% \mathrm{NaOH}$ solution for 12 hours then dried in the oven, the length of fiber used is $40 \mathrm{~mm}$. Variation in the percentage of fiber by reducing the weight of the volume of cement in the mixture is $0 \%, 5 \%, 10 \%, 15 \%, 20 \%$. Results The average flexural strength produced at each fiber variation is $0 \%(3.51 \mathrm{Mpa}), 5 \%$ (4.18 Mpa), 10\% (4.09 Mpa), 15\% (4.53 Mpa) and 20\% (4.62 Mpa). From this study shows that the use of fiber in concrete mixes shows an increase in the flexural strength of concrete at fiber percentage points of $5 \%, 10 \%, 15 \%$, and $20 \%$, when compared to normal concrete $(0 \%)$.
\end{abstract}

Keywords: flexural strength, oil palm empty bunches fiber, concrete.

Prilaku Kuat Lentur Beton Terhadap Penambahan Serat Tanda Kosong Kelapa Sawit Muliadi, Sofyan, Yusti Hajar 


\section{Pendahuluan}

Beton salah satu bahan konstruksi yang sering digunakan untuk bangunan gedung, jembatan, jalan, dan lain-lain. Beton adalah campuran antara semen, agregat halus, agregat kasar, air atau dengan menambah zat additive yang kemudian mengeras membentuk benda padat.

Kekuatan konstruksi beton sangat dipengaruhi pada kualitas semen, jenis material yang digunakan, ikatan/adesi antar material, pemadatan dan perawatannya. Kelebihan beton normal maupun beton ringan sama-sama memiliki kuat tekan yang tinggi tetapi lemah terhadap kuat lentur. Untuk itu dalam pemakaiannya diperlukan tulangan dan bahan tambahan lainnya untuk memperbaiki karakteristik beton agar berkualitas. Pada beberapa negara maju seperti Amerika dan Inggris, telah dikembangkan konsep perbaikan kelemahan sifat beton tersebut dengan menambahkan serat (fiber) pada adukan beton (Dwi P., Muchtar F, 2006).

Konsep dasarnya adalah untuk menulangi beton secara alami dengan serat yang disebarkan acak ke dalam adukan beton, sehingga dapat mencegah terjadinya retakan yang terlalu dini baik akibat beban maupun akibat panas hidrasi. Banyak sekali serat yang dapat digunakan untuk memperbaiki sifat - sifat beton. Jenis serat tersebut antara lain serat baja, serat plastik, serat karbon, serat alam, dan serat fiber glass.

Pada penelitian ini serat yang digunakan adalah serat alam, yaitu serat tandan kosong kelapa sawit yang merupakan limbah dari pabrik minyak sawit. Mengingat Indonesia merupakan salah satu negara terbesar penghasil kelapa sawit di dunia dengan luas tanaman kelapa sawit sebesar 8,43 juta Ha dari luas total tanaman kelapa sawit di Indonesia menghasilkan serat tandan kosong kelapa sawit mencapai 37 juta ton/tahun yang secara keseluruhan belum dimanfaatkan secara maksimal. Selama ini limbah tandan tersebut hanya dimanfaatkan untuk pupuk kelapa sawit, kapas sofa dan sebagian lainnya dibuang sebagai sampah. Padahal tandan kelapa sawit ini mempunyai kandungan serat yang cukup tinggi mengandung selulosa dan holoselulosa (Subyakto, 2012).

Untuk itu peneliti mencoba memanfaatkan serat tandan kosong sawit ini sebagai bahan pengisi pada campuran beton, dan diharapkan dapat memperbaiki sifat-sifat mekanik campuran beton.

\section{Metode Penelitian}

Secara garis besar tahapan penelitian ini meliputi persiapan, pelaksanaan, dan analisis data. Pada tahap persiapan, penelitian ini dimulai dengan studi literatur yang dilanjutkan dengan persiapan dan pengadaan material, proses pembuatan serat, pengujian sifat fisis material, mix design

\subsection{Material}

Material yang digunakan pada penelitian ini terdiri dari Semen portland (tipe I), pasir lolos saringan no 4 ukuran $4,75 \mathrm{~mm}$, agregat kasar batu pecah lolos saringan no 19 tertahan di saringan no 4, bahan tambah serat tandan kosong kelapa sawit (STKKS), air dan $\mathrm{NaOH} 10 \%$. 


\subsection{Proses Pembuatan Serat}

Bahan baku tandan kosong kelapa sawit diperoleh dari Kuala Simpang Aceh Tamiang yang masih basah dijemur dan sudah dicacah dengan menggunakan mesin, selanjutkan dipisahkan untuk diambil seratnya, serat yang digunakan adalah serat yang telah dipotong-potong dari pabriknya kemudian serat direndam mengunakan larutan $\mathrm{NaOH}$ berdasarkan Nuria Gurning (2013). serat tandan kosong kelapa sawit (TKKS) yang telah dipotong-potong, lalu direndam dengan menggunakan $10 \%$ larutan $\mathrm{NaOH}$ selama 12 jam, dikeringkan dalam oven pada suhu $60^{\circ} \mathrm{C}$ selama $12 \mathrm{jam}$.

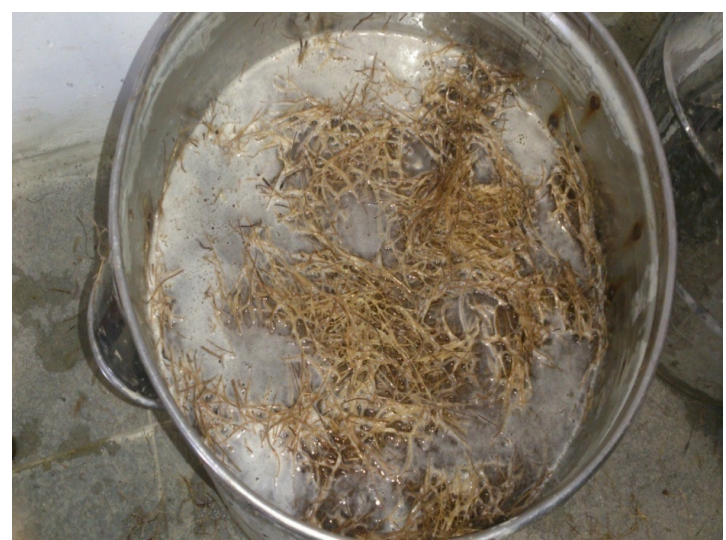

Gambar 1 Perendaman serat dengan $10 \%$ larutan $\mathrm{NaOH}$

\subsection{Pengujian Sifat Fisis Material}

Pengujian material diperlukan untuk mendapatkan bahan campuran beton yang memenuhi spesifikasi material, dalam hal ini sesuai dengan standar SNI (Standar Nasional Indonesia). Selain itu, pengujian material juga untuk menganalisis sifat dan karakteristik beton yang dibuat sesuai dengan kinerja tertentu yang diharapkan baik pada saat beton segar ataupun beton telah mengeras.

Material yang diuji yaitu semen, agregat halus, agregat kasar. pemeriksaan sifat-sifat fisis agregat yang digunakan untuk pembuatan benda uji yaitu meliputi kadar air, berat volume, berat jenis, absorbsi, analisis saringan, dan kehalusan semen.

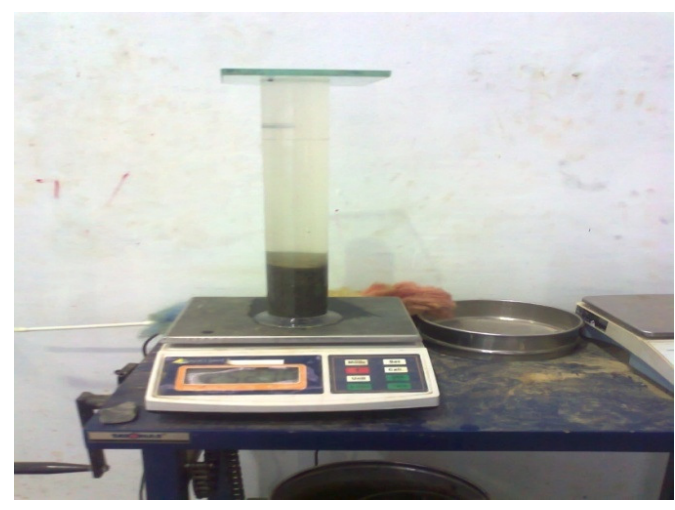

Gambar 2 Pemeriksaan berat jenis agregat halus

Prilaku Kuat Lentur Beton Terhadap Penambahan Serat Tanda Kosong Kelapa SawitMuliadi, Sofyan, Yusti Hajar 


\subsection{Perencanaan Campuran Beton (Mix Design)}

Dalam pembuatan benda uji, dilakukan rencana campuran memakai perhitungan SNI 03-2834-2000 (Tata Cara Pembuatan Rencana Campuran beton Normal). Tata cara ini meliputi persyaratan umum dan persyaratan teknis perencanaan proporsi campuran beton, dalam merencanakan proporsi campuran beton tidak menggunakan bahan tambah untuk menghasilkan mutu beton sesuai dengan rencana penelitian.

Menurut Nugraha, P., Antoni (2007), prosedur perencanaan meliputi tiga tahap. Tahap pertama adalah persyaratan penggunaan struktur beton tersebut, yang terdiri dari jenis struktur, kondisi lingkungan, ukuran penampang, kualitas material, dan koefisien variasi. Tahap kedua adalah dasar perencanaan, meliputi ukuran butir terbesar, slump, kekuatan rencana, ketahanan, kelecakan, kekuatan semen, dan jenis admixture. Tahap ketiga adalah perhitungan, meliputi faktor air semen, jumlah air, faktor agegat, dan hitungan semua proporsi.

Menurut Murdock, L. J., Brook, K.M (1991), tujuan dari perencanaan campuran beton ialah untuk menentukan proporsi semen, agregat halus dan kasar, serta air yang memenuhi persyaratan berikut ini:

1. Kekuatan desak: Kuat desak yang dicapai pada 28 hari (atau umur yang ditentukan) harus memenuhi persyaratan yang diberikan oleh perencana konstruksinya.

2. Workabilitas: Untuk memenuhi workabilitas yang cukup guna pengangkutan, pencetakan dan pemadatan beton sepenuhnya dengan peralatan yang tersedia.

3. Durabilitas: Durabilitas atau sifat awet berhubungan denga kekuatan desak; semakin besar kekuatan, makin awet betonnya.

4. Penyelesaian akhir dari permukaan beton: Kohesi yang kurang baik dapat merupakan salah satu sebab penyelesaian akhir yang kurang baik, bilamana beton dicetak pada acuan tegak, seperti goresan pasir dan variasi warna, dan dapat juga mendatangkan kesukaran di dalam menambal bidang horizontal menjadi suatu penyelesaian akhir yang halus dan padat.

\subsection{Komposisi Campuran Mix Design}

Perhitungan komposisi campuran beton dihitung dengan menggunakan metode SNI untuk beton normal. Proporsi campuran dilakukan untuk mengetahui banyaknya material yang akan digunakan dalam campuran beton, material yang akan digunakan dalam campuran beton di antaranya adalah air, semen, agregat kasar, agregat halus dan serat tandan kosong kelapa sawit.

Tabel 1 Komposisi campuran dengan variasi pemakaian serat tandan kosong sawit

\begin{tabular}{lccccc}
\hline $\begin{array}{c}\text { Nama benda } \\
\text { uji }\end{array}$ & \multicolumn{6}{c}{ Berat Material Untuk Volume $\mathbf{0 . 0 4 5} \mathbf{~ m}^{\mathbf{3}}$, fas } & $\mathbf{0 . 4 8 5}$ \\
\hline \multicolumn{1}{c}{ Persentase } & $\mathbf{0}$ & $\mathbf{5 \%}$ & $\mathbf{1 0 \%}$ & $\mathbf{1 5 \%}$ & $\mathbf{2 0 \%}$ \\
\hline Air & 10,198 & 10,198 & 10,198 & 10,198 & 10,198 \\
\hline Semen & 18,845 & 17,902 & 16,960 & 16,018 & 15,076 \\
\hline Pasir & 31,078 & 31,078 & 31,078 & 31,078 & 31,078 \\
\hline Kerikil & 44,884 & 44,884 & 44,884 & 44,884 & 44,884 \\
\hline Serat & 0,000 & 0,035 & 0,070 & 0,105 & 0,140 \\
\hline
\end{tabular}




\subsection{Pembuatan Benda Uji}

Pembuatan benda uji dilakukan dengan sangat teliti agar hasil pengujian menjadi lebih tinggi tingkan akurasinya sebagai berikut:

a. Pertama-pertama mempersiapkan alat-alat yang digunakan untuk pekerjaan ini yaitu: cetakan benda uji, tongkat pemadat dari besi, martil karet, sendok beton, dan peralatan slump test. Jumlah sampel yang dibuat sebanyak 15 buah benda uji berbentuk balok yang berukuran $60 \mathrm{~cm} \times 15 \mathrm{~cm} \times 15 \mathrm{~cm}$, untuk setiap variasi serat akan dibuat masing-masing 3 benda uji.

b. Kemudian dimasukan agregat kasar dan agregat halus yang telah ditimbang kedalam molen, diputar hingga agregatnya tercampur rata.

c. Kemudian dimasukan semen, diputar sambil memasukan air sedikit demi sedikit hingga campuran terlihat homogen.

d. Kemudian ditambahkan serat sedikit demi sedikit ke dalam campuran beton dan molen dibiarkan berputar agar campuran beton dan serat merata.

e. Setelah itu dilakukan pengujian slump test hingga, hasilnya dicatat sebagai hasil penelitian.

f. Adukan beton selanjutnya dimasukkan ke dalam cetakan yang sudah disiapkan dan dipadatkan dengan menggunakan palu karet. Cetakan dibiarkan selama \pm 24 jam. Setelah beton mengeras maka dilakukan perawatan selama 28 hari dan dilanjutkan dengan uji kuat tarik lentur.

\subsection{Perawatan Benda Uji}

Perawatan benda uji dilakukan dengan cara perendaman. Perawatan beton ini bertujuan untuk menjamin proses hidrasi semen dapat berlangsung dengan sempurna, sehingga retak-retak pada permukaan beton dapat dihindari serta mutu beton yang diinginkan dapat tercapai. Selain itu kelembaban pemukaan beton juga dapat menambah ketahanan beton terhadap pengaruh cuaca dan lebih kedap air. Cara perendamannya, setelah 24 jam maka cetakan beton dibuka, lalu dilakukan perendaman terhadap sampel beton tersebut. Perendaman dilakukan sampai umur beton 28 hari. Sebelum beton direndam terlebih dahulu diberi nama pada permukaannya.

\subsection{Pengujian Kuat Lentur Beton}

Kuat lentur benda uji sangat dipengaruhi oleh faktor air semen, komposisi serat, bentuk dan ukuran benda uji, serta mutu material yang baik seperti umur semen yang masih layak digunakan. Alat yang digunakan untuk penentuan kekuatan benda uji dilakukan dengan menggunakan mesin uji kuat lentur beton.
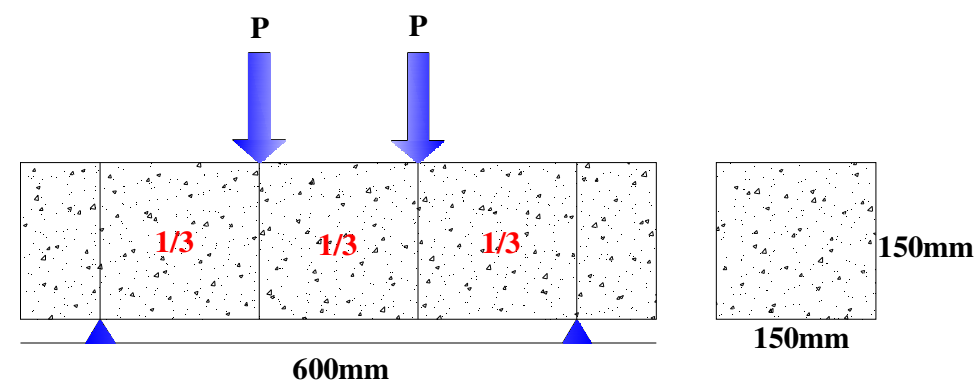

Gambar 3 Pengujian kuat tekan lentur beton 
Pengujian beton dilakukan pada umur beton 28 hari. Langkah-langkah pengujiannya adalah sebagai berikut:

a. Sampel benda uji diangkat dari rendaman, kemudian di diamkan dalam 1 hari

b. Menimbang dan mencatat berat sampel beton, kemudian diamati apakah terdapat cacat pada beton sebagai bahan laporan

c. Buat garis-garis melintang sebagai tanda titik perletakan dan titik pembebanan, jarak titik perletakan dari satu sisi ke sisi yang lain yaitu $45 \mathrm{~cm}$, untuk jarak pembebanan dari satu sisi ke sisi lain yaitu $15 \mathrm{~cm}$ dan panjang dua sisi diluar titik perletakan yaitu $7,5 \mathrm{~cm}$.

d. Meletakkan sampel beton ke dalam alat penguji, lalu menghidupkan mesin dan secara perlahan alat menekan sampel beton

e. Mencatat hasil kuat tarik lentur beton untuk tiap sampelnya.

\section{Hasil dan Pembahasan}

Hasil pengujian kuat lentur yang diperoleh berdasarkan pengujian diperlihatkan pada Tabel 2 berdasarkan persen serat 0\%, 5\%, 10\%. 15\% dan 20\% yang diuji pada umur 28 hari.

Tabel 2 Kuat tarik lentur beton rata-rata

\begin{tabular}{cccccc}
\hline No & $\begin{array}{c}\text { Serat } \\
(\%)\end{array}$ & $\begin{array}{c}\text { Umur } \\
\text { (hari) }\end{array}$ & $\begin{array}{c}\text { Berat } \\
\text { beton }(\mathbf{k g})\end{array}$ & $\begin{array}{c}\text { Kuat Lentur } \\
\text { Rata Rata } \\
(\mathbf{M p a})\end{array}$ & $\begin{array}{c}\text { Peningkatan } \\
\mathbf{\%}\end{array}$ \\
\hline 1 & $0 \%$ & 28 & 31,634 & 3,51 & - \\
\hline 2 & $5 \%$ & 28 & 31,290 & 4,18 & 19,088 \\
\hline 3 & $10 \%$ & 28 & 31,107 & 4,29 & 22,222 \\
\hline 4 & $15 \%$ & 28 & 30,956 & 4,53 & 29,059 \\
\hline 5 & $20 \%$ & 28 & 30,797 & 4,62 & 31,623 \\
\hline
\end{tabular}

Dari Tabel 2 dapat dilihat bahwa penggunaan serat dalam beton dapat mempengaruhi kuat lentur beton, yaitu dapat menaikkan nilai kuat lentur beton dari pada beton tanpa penggunaan serat. Hal ini dikarenakan penulangan serat dalam beton terjadi secara alami, dan dapat menulangi beton dengan baik sesuai dengan arah beban yang diterimanya.

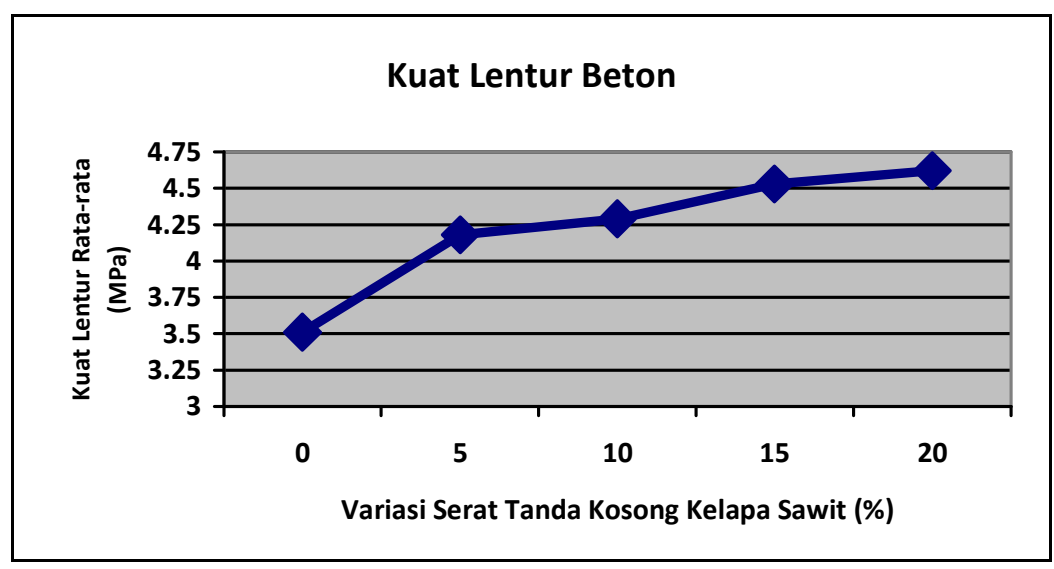

Gambar 4 Grafik kuat lentur beton 
Gambar 4 menunjukkan grafik kuat lentur beton, dimana penggunaan serat tandan kosong kelapa sawit $(5 \%, 10 \%, 15 \%$, dan 20\%) dari berat volume semen diperoleh kuat lentur rata-rata sebesar 4,18 Mpa untuk (5\%) penambahan serat tandan sawit, 4,29 Mpa pada penambahan serat (10\%), 4,53 Mpa pada penambahan serat (15\%), dan 4,62 Mpa pada penambahan serat (20\%). Dari hasil dapat disimpulkan bahwa pengunaan serat pada campuran beton dapat menaikkan nilai kuat lentur dari pada beton tanpa serat.

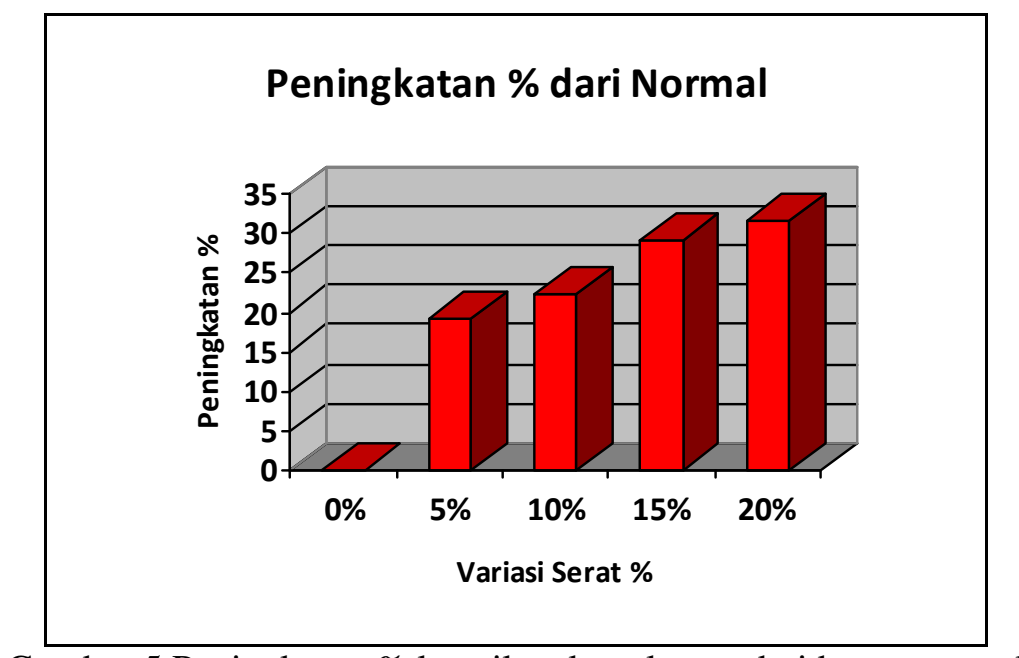

Gambar 5 Peningkatan \% kenaikan kuat lentur dari beton normal

Gambar 5 menunjukkan grafik Peningkatan prosentase kenaikan kuat lentur dari beton normal, dimana penggunaan serat tandan kosong kelapa sawit $(5 \%$, $10 \%$, 15\%, dan 20\%) mengalami peningkatan secara berurut sebesar 19,088\%, $22,222 \%, 29,059 \%$, dan $31,263 \%$. Peningkatan maksimum terjadi pada variasi serat $20 \%$ sebesar $31,263 \%$.

\section{Kesimpulan dan Saran}

\subsection{Kesimpulan}

Dari hasil penelitian yang telah dilakukan didapatkan bahwa penggunaan serat tandan kosong kelapa sawit meningkatkan kuat lentur beton. Dengan variasi (5\%) diperoleh kuat lentur beton rata-rata sebesar 4,18 Mpa, penambahan serat (10\%) diperoleh kuat lentur beton rata-rata sebesar 4,09 Mpa, penggunaan serat (15\%) diperoleh kuat lentur beton rata-rata sebesar 4,53 Mpa dan pada penggunaan serat (20\%) diperoleh kuat lentur rata-rata sebesar 4,62 Mpa.

Peningkatan kuat lentur beton mengalami peningkatan secara berurutan sebesar 19,088\%, 22,222\%, 29,059\%, dan 31,263\% dari kuat lentur normal. Peningkatan maksimum terjadi pada variasi serat $20 \%$ sebesar $31,263 \%$. Ini membuktikan bahwa sistem kerja serat sebagai penahan gaya tarik bekerja secara baik. penambahan serat tandan kosong kelapa sawit memberikan manfaat positif untuk memperbaiki sifat-sifat mekanik beton dalam perkembangan teknologi beton. 


\subsection{Saran}

Penelitian ini hanya dilakukan dengan penambahan variasi banyaknya serat $0 \%, 5 \%, 10 \%, 15 \%$ dan $20 \%$ dengan panjang serat yang digunakan $40 \mathrm{~mm}$. Maka perlu adanya penelitian lebih komprehensif terhadap penelitian selanjutnya tentang pemanfaatan limbah tandan kosong kelapa sawit sebagai beton serat, baik diteliti dari variasi dan panjang serat yang berbeda atau penggunaan serat yang lainya. Pengunaan serat tandan kosong kelapa sawit juga dapat digunakan sebagai asumsi kuat tekan beton. Agar didapat kajian lebih mendalam tentang perilaku lentur beton.

\section{Daftar Kepustakaan}

Badan Standarisasi Nasional, 2000, SNI 03-2834-2000 Tata Cara Pembuatan Rencana Campuran Beton Normal. BSNI, Jakarta

Dwi P, Denny, dan Muchtar F, Nanang, 2006. Analisis Pengaruh Penambahan Serat Polypropylene Pada Kuat Tekan dan Kuat Tarik Beton Mutu K 500. Universitas Diponegoro, Semarang.

Gurning, Nuria, 2013. Pembuatan Beton Serat Tandan Kosong Kelapa Sawit. Jurnal Ilmu Pengetahuan dan Teknologi, Tangerang.

Murdock, L. J, dan K. M. Brook, 1991. Bahan dan Praktek Beton, 4th Edition, Stephanus Hindarko. Erlangga, Jakarta

Nugraha, P. Antoni, 2007. Teknologi Beton. Andi, Yogyakarta.

Subyakto, 2012. Serat Alam Sebagai Bahan Baku Industri Biokomposit. www.xa.yimg.com. diunduh tanggal 04 September 2013. 